\title{
Expression of Aquaporin 1, 5 and 9 in the Ovarian Follicles of Cycling and Early Pregnant Pigs
}

\author{
A. SKOWRONSKA ${ }^{1}$, P. MLOTKOWSKA ${ }^{2}$, M. ELISZEWSKI ${ }^{3}$, S. NIELSEN ${ }^{4}$, \\ M. T. SKOWRONSKI ${ }^{2,5}$
}

${ }^{1}$ Department of Human Physiology, Faculty of Medical Sciences, University of Warmia and Mazury in Olsztyn, Poland, ${ }^{2}$ Department of Animal Physiology, Faculty of Biology and Biotechnology, University of Warmia and Mazury in Olsztyn, Poland, ${ }^{3}$ Department of Gynecology and Obstetrics, Faculty of Medical Sciences, University of Warmia and Mazury in Olsztyn, Poland, ${ }^{4}$ Department of Health Science and Technology, Faculty of Medicine, Aalborg University, Aalborg, Denmark, ${ }^{5}$ Institute of Veterinary, Poznań University of Life Sciences, Poznań, Poland

Received May 7, 2014

Accepted August 8, 2014

On-line October 15, 2014

\begin{abstract}
Summary
Aquaporins (AQPs) are water channel proteins responsible for water homeostasis and important for proper functioning of all body systems, including reproductive structures. This study was designed to determine their localization and quantitative changes in the pig ovary during different stages of the estrous cycle and early pregnancy. The expression of AQP 1, 5 and 9 proteins was determined by immunocytochemistry and Western blot analyses. AQP1 was found in the plasma membranes of capillary endothelium, AQP5 - in the plasma membranes of granulosa cells of developing follicles and flattened follicle cells of the primordial follicles, and AQP9 - in granulosa cells of the developing follicles. In the cyclic pigs, the expression of AQP1 and 5 proteins was the highest on Days 18-20, but did not change significantly between Days 2-4, 10-12 and 14-16 of the cycle. In pregnant pigs (Days 14-16 and 30-32), the expression of AQP1 and 5 did not change and was similar to that observed during Days 10-12 and 14-16. In turn, AQP9 expression did not change between all studied periods. In conclusion, studied AQP are localized in different cells populations, the endothelial and granulosa cells, and AQP1 and 5 seem to be crucial for follicular development in pigs.
\end{abstract}

\section{Key words}

Aquaporins • Protein expression • Ovary • Pig

\section{Corresponding author}

M. T. Skowronski, University of Warmia and Mazury in Olsztyn,
Department of Animal Physiology, Oczapowskiego 1A, 10-718 Olsztyn, Poland. Fax: +48 89 5233937. E-mail: skowron@uwm.edu.pl

\section{Introduction}

Follicular development of the ovary is the result of positive and negative factors acting simultaneously on follicular growth and follicular atresia in gilts (Clark et al. 1975). During the luteal phase of the estrous cycle successive populations of pig primordial (non developing) follicles (Greenwald and Moor 1989) initiate growth and provide the pool of intermediate sized follicles $(3-6 \mathrm{~mm})$ that will eventually be recruited into the ovulatory population after luteolysis (Wiesak et al. 1992). The growth of follicles during early pregnancy in the pigs is altered in comparison with that during the luteal phase of the estrous cycle and the process of follicles maturation is suppressed. During the follicular phase small antral follicles develop into large, preovulatory follicles (Prunier et al. 1987, Noguchi et al. 2010). Antral expansion occurs when fluid, derived from serum, accumulates in the interior of the follicle. However, the precise mechanism involving large amounts of fluid passing into the antral cavity of the follicles remains unknown. Recently, Rodgers and Irving-Rodgers (2010) have proposed that production of hyaluronan and

PHYSIOLOGICAL RESEARCH • ISSN 0862-8408 (print) • ISSN 1802-9973 (online)

(c) 2015 Institute of Physiology v.v.i., Academy of Sciences of the Czech Republic, Prague, Czech Republic

Fax +420 241062 164, e-mail: physres@biomed.cas.cz, www.biomed.cas.cz/physiolres 
versican by granulosa cells generates an osmotic gradient that drives fluid from the thecal vasculature and that the granulosa cells can facilitate transcellular water transport via aquaporins.

Mammalian aquaporins (AQPs) are members of hydrophobic integral membrane channel proteins that primary transport water across the plasma membrane (Agre et al. 2002). There are 13 AQP subtypes (AQP012) that are divided into three subgroups: classical aquaporins (AQP0, 1, 2, 4, 5, 6, 8), aquaglyceroporins (AQP3, 7, 9, 10) and superaquaporins (AQP11, 12). Most AQPs have a unique tissue specific pattern of expression where they may play important physiological functions (Carbrey and Agre 2009, Verkman 2008). The new insight into the regulation and functions of AQPs demonstrates their important role in reproductive physiology; see review Huang et al. (2006) and Zhang et al. (2012).

In the available literature, only a few studies have been reported about the localization and expression of AQPs in the ovary. McConnell et al. (2002) investigated the mechanism of the water permeability in the rat antral follicle. It has been demonstrated that water permeability mediated by AQPs can control the rate of apoptosis in rats granulosa cells (Jablonski et al. 2004). West-Farrell et al. (2009) indicated that levels of AQP7 and 8 increased in follicles which do not form antrum and produce appropriate levels of steroids. It has also been reported that AQP9 was present in the nucleus, cytoplasm and cell membrane of the granulose cells of patients with polycystic ovary syndrome (PCOS) and was lower in granulosa cells of the women with PCOS syndrome than controls (Qu et al. 2010). Thoroddsen et al. (2011) showed the presence of AQP1-4 in isolated human granulosa and theca cells. Our laboratory revealed the expression of AQPs in the reproductive system of gilts (Skowronski 2010, Skowronski et al. 2009, 2011a,b). However, there are no studies concerning localization and quantitative expression of AQPs in the ovary of cycling and early pregnant pigs.

Therefore, the present study was designed to examine the expression pattern of AQP1, 5 and 9 in the ovary of gilts during the estrous cycle and pregnancy.

\section{Materials and Methods}

\section{Experimental animals}

All experiments were performed in accordance with the principles and procedures of Animal Ethics
Committee of the University of Warmia and Mazury in Olsztyn. Mature gilts (Large White $\times$ Polish Landrace), 7 to 8 months old, weighing $120-130 \mathrm{~kg}$ were obtained from private breeders. Gilts were observed daily for estrus behavior in the estrous cycle, and they were used during their third consecutive normal estrous cycle. A total of thirty gilts were assigned to one of six experimental groups ( $\mathrm{n}=5$ per group) as follows: the early-luteal (Days 2-4), the mid-luteal (Days 10-12 of the cycle, coinciding with a period of full active corpora lutea corresponding to the activity of corpora lutea in the period of pregnancy), the late-luteal (Days 14-16 of the cycle, coinciding with a period of luteal regression and development of a new cohort of follicles) and the follicular group (Days 18-20) of the estrous cycle, as well as the early implantation (Days 14-16) and the postimplantation placentation group (Days 30-32) of gestation. Additionally, stage of the cycle was confirmed according to Akins and Morrissette (1968). Gilts assigned to the pregnant group were naturally bred on the second day of estrus. Pregnancy was detected by ultrasound scanning before killing the gilts (Days 30-32). Additionally, pregnancy was confirmed by the presence of embryos after flushing uterine horns with $20 \mathrm{ml}$ of sterile saline (Days 14-16). Moreover, plasma concentration of estradiol $\left(\mathrm{E}_{2}\right)$ and progesterone $\left(\mathrm{P}_{4}\right)$ was measured to confirm the stages of the cycle and pregnancy. Plasma concentration of $\mathrm{E}_{2}(\mathrm{pg} / \mathrm{ml})$ and $\mathrm{P}_{4}$ (ng/ml) were as follows: on Days 2-4 (0.73 \pm 0.09 and $7.2 \pm 0.97)$; Days 10-12 (0.84 \pm 0.15 and 16.44 \pm 2.18$)$; Days 14-16 (2.76 \pm 0.44 and 1.03 \pm 0.19$)$; Days 18-20 (19.36 \pm 2.17 and $0.91 \pm 0.18)$ of the estrous cycle, and on Days 14-16 (1.47 \pm 0.21 and 21.24 \pm 3.05$)$; Days 30-32 (1.29 \pm 0.18 and $23.45 \pm 3.39)$ of pregnancy, respectively. Ovary was separated from each gilts and frozen in liquid nitrogen immediately after dissection and then stored at $-80^{\circ} \mathrm{C}$ until Western blot analysis. For immunohistochemistry, tissues were fixed by immersion in $4 \%$ paraformaldehyde for $24 \mathrm{~h}$ (Skowronski et al. 2007).

\section{SDS-PAGE and Western blot}

Western blot analysis was performed as described previously by (Skowronski et al. 2007). Briefly, equal amounts of porcine tissue lysates were loaded into $12.5 \%$ polyacrylamide gels and proteins were separated by electrophoresis and electro-transferred onto nitrocellulose membranes (Hybond ECL RPN3032D, Amersham Pharmacia Biotech, Little Chalfont, UK) for 
$1 \mathrm{~h}$ at $100 \mathrm{~V}$. The membranes were blocked with $5 \%$ milk in PBS-T (80 mM Na $2 \mathrm{HPO}_{4}, 20 \mathrm{mM} \mathrm{NaH} \mathrm{PO}_{4}$, $100 \mathrm{mM} \mathrm{NaCl}, \mathrm{pH} 7.5$ and $0.1 \% \mathrm{vol} / \mathrm{vol}$ Tween 20) for $1 \mathrm{~h}$. After washing, the membranes were incubated overnight at $5{ }^{\circ} \mathrm{C}$ with anti-AQPs (anti-AQP1, 1:200; anti-AQP5, 1:1000; anti-AQP9, 1:100) or $\beta$-actin $(1: 1000)$ antibodies.

The membranes were washed and incubated with horseradish peroxidase-conjugated goat anti-rabbit IgG secondary antibody (P448, diluted 1:3000, Dako A/S, Glostrup, Denmark) in PBS-T for $1 \mathrm{~h}$. After washing with PBS-T, the sites of antibody-antigen reaction were visualized with an enhanced chemiluminescence (ECL) system (Amersham Pharmacia Biotech, Little Chalfont, UK) and exposure to photographic film (Hyperfilm ECL, RPN3103K, Amersham Pharmacia Biotech, Little Chalfont, UK).The results of Western blotting were quantified by densitometric scanning of immunoblots with GelScan for Windows ver. 1.45 software (Kucharczyk, Poland). Data were expressed as a ratio of AQP proteins relative to actin protein in OD. Negative controls for all WB analyses were performed by both omitting the primary antibodies specific to each AQP and using non-immune $\mathrm{IgG}$, and no specific immunostaining was observed (data not shown).

\section{Immunohistochemistry}

For preparation of paraffin-embedded tissue sections (4- $\mu \mathrm{m}$ thickness), the tissues were dehydrated in ethanol followed by xylene and finally embedded in paraffin (Skowronski et al. 2009). The staining was carried out using indirect immunoperoxidase. The sections were dewaxed and rehydrated. For immunoperoxidase labeling, endogenous peroxidase was blocked by $0.5 \% \mathrm{H}_{2} \mathrm{O}_{2}$ in absolute methanol for $10 \mathrm{~min}$ at room temperature. To reveal antigens, the sections were submerged in $1 \mathrm{mM}$ Tris solution ( $\mathrm{pH}$ 9.0) supplemented with $0.5 \mathrm{mM}$ EGTA and heated in a microwave oven. After the treatment, the sections were left for $30 \mathrm{~min}$ in the buffer for cooling. Nonspecific binding of $\mathrm{IgG}$ was eliminated by incubating the sections in $50 \mathrm{mM} \mathrm{NH}{ }_{4} \mathrm{Cl}$ for $30 \mathrm{~min}$, followed by blocking in PBS supplemented with $1 \%$ BSA, $0.05 \%$ saponin and $0.2 \%$ gelatin. The sections were incubated overnight at $4{ }^{\circ} \mathrm{C}$ with primary antibodies (anti-AQP1, 1:200; antiAQP5, 1:1000; anti-AQP9, 1:100 or anti- $\beta$-actin, 1:1000, Sigma, USA) diluted in PBS supplemented with $0.1 \%$ BSA and $0.3 \%$ Triton X-100. The sections were rinsed with PBS supplemented with $0.1 \%$ BSA, $0.05 \%$ saponin and $0.2 \%$ gelatin, and then incubated with horseradish peroxidase-conjugated secondary antibody (P448, diluted 1:200, Dako A/S, Glostrup, Denmark). Labeling was visualized by $0.05 \% \quad 3,3$ diaminobenzidine tetrahydrochloride (DAB) and sections were counterstained with Mayer's hematoxylin. The microscopy was carried out using a Olympus light microscope (BX51, Japan). Negative controls for all IHC analyses were performed by both omitting the primary antibodies specific to each AQP and using non-immune IgG, and no specific immunostaining was observed (data not shown).

\section{Primary antibodies}

In the present study, affinity-purified polyclonal antibodies to AQPs were used (SulfoLink Kit, Pierce). The antibodies to AQP1, AQP5 and AQP9 were previously characterized, respectively by Terris et al. (1996), Nielsen et al. (1997) and Carbrey et al. (2003). Moreover, the anti- $\beta$-actin antibody was used (cat. no. A2066, Sigma-Aldrich). In addition, immunoglobulins from non-immunized rabbit were used as a negative control.

\section{Statistical analysis}

All data were analyzed by one-way ANOVA and least significant difference (LSD) post hoc test and were reported as the means \pm S.E.M. from five independent observations. Statistical analyses were performed using the Statistica program (StatSoft Inc., Tulsa, USA). Values for $p<0.05$ were considered statistically significant.

\section{Results}

The results demonstrated that AQP1, 5, and 9 were clearly detected in all studied stages (see "Materials and Methods") of the estrous cycle and pregnancy. AQP1 immunoreactivity was detected in the capillary endothelium plasma membranes of the ovary (Fig. 1A-F). As a positive control, AQP1 labeling was seen in the apical and basolateral plasma membrane in the proximal tubule cells of pig kidney (Fig. 1G). In cyclic gilts, the expression of AQP1 protein did not change significantly between Days 2-4, 10-12 and 14-16 but increased $(p<0.05)$ on Days 18-20 (Fig. 2A). The expression of AQP1 tended to be higher on Days 2-4 and 14-16 than on Days $10-12, p=0.08$ and $p=0.07$, respectively (Fig. 2A). In pregnant gilts, the expression of AQP1 did not change significantly during the onset and the end of implantation 
process (Fig. 2B). Moreover, the expression of AQP1

and late-luteal phases of the estrous cycle (Fig. 2C).

during early pregnancy did not differ compared to mid-

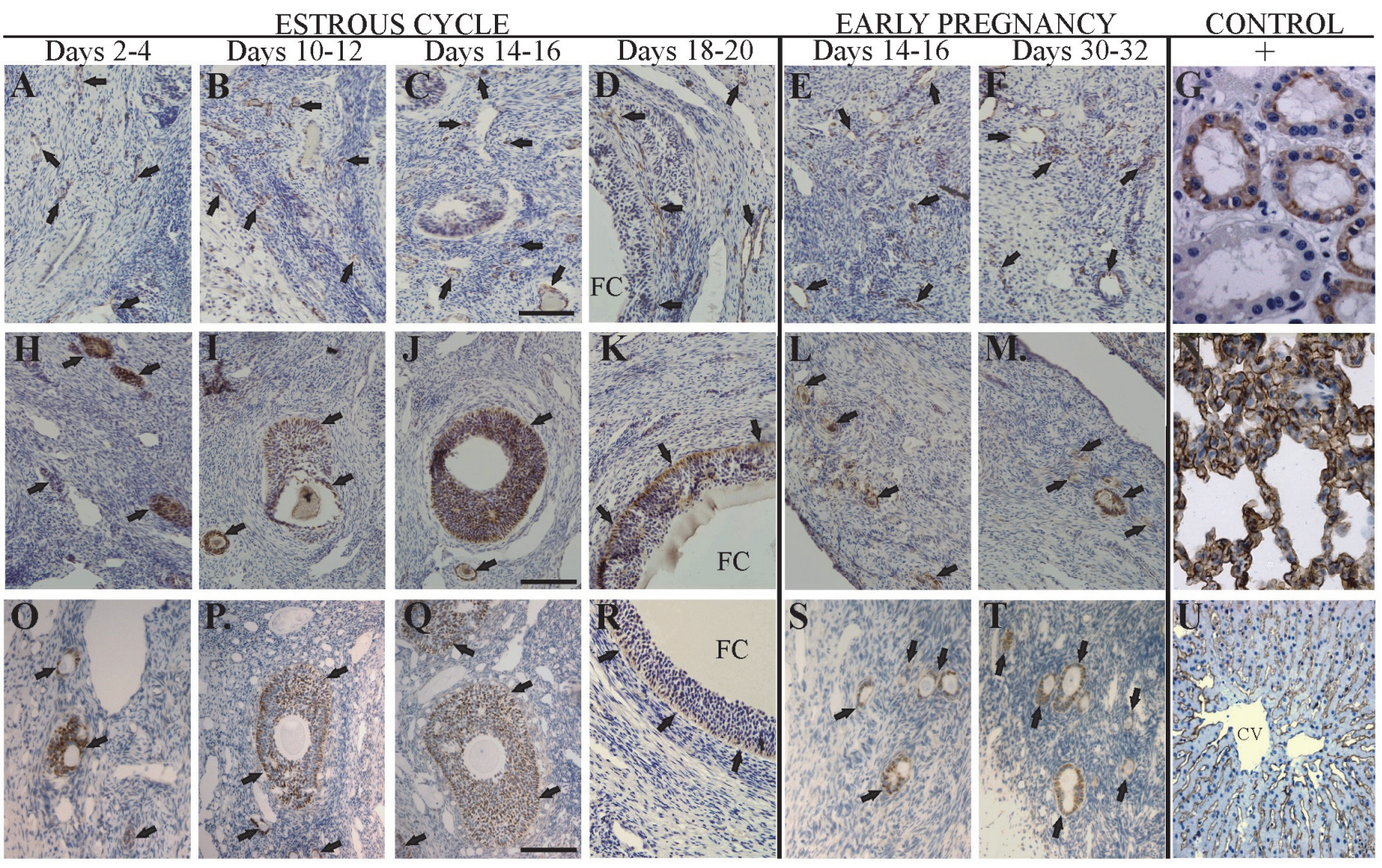

Fig. 1. Immunolocalization of $A Q P 1,5$ and 9. Anti-AQP1 antibody labels capillary endothelium (arrows) of the pig ovary during the estrous cycle (A-D) and early pregnancy (E-F). Immunoperoxidase labeling of AQP1 from the pig kidney cortex (positive control) (G). The labeling is seen in both of the apical cell membrane and in the basolateral cell membrane in proximal tubule cells. AQP5 antibody stains the plasma membranes of granulosa cells (arrows) and flattened follicle cells of the primordial follicles (arrows) of the ovary during the estrous cycle (H-K) and pregnancy (L-M). The anti-AQP5 labels apical membrane of type I pulmonary epithelial cells of the pig (positive control) (N). AQP9 labels the granulosa cells of the developing follicles (arrows) during the estrous cycle (0-R) and pregnancy (S-T). Immunoperoxidase labeling of AQP9 from the pig liver (positive control) (U). Sections were counterstained with Mayer's hematoxylin. FC, follicular cavity; $\mathrm{CV}$, central vein. Bar $=50 \mu \mathrm{m}$.

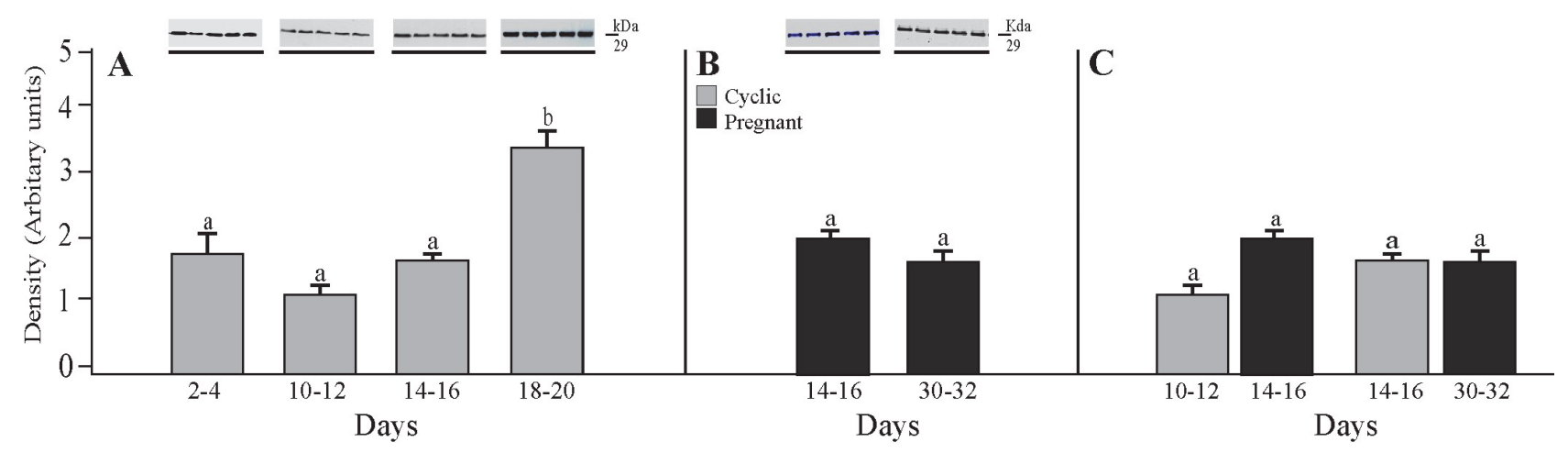

Fig. 2. Western blot analysis of AQP1 expression. Expression of AQP1 assessed by Western blotting in the porcine ovary on Days 2-4, 10-12, 14-16 and 18-20 of estrous cycle (A) as well as on Days 14-16 and 30-32 of pregnancy (B). Densitometric analyses of AQP1 protein levels normalized against $\beta$-actin are summarized in $A$ and $B$ for ovarian expression of AQP1 during studied stages. Comparison of AQP1 expression determined by Western blotting in porcine ovary, between two stages of the cycle and two periods of pregnancy (C). Values are the mean \pm SEM $(n=5)$. ${ }^{a, b}$ Means with different superscripts are significantly different. 




Fig. 3. Western blot analysis of AQP5 expression. Expression of AQP5 assessed by Western blotting in the porcine ovary on Days 2-4, $10-12,14-16$ and 18-20 of estrous cycle (A) as well as on Days 14-16 and 30-32 of pregnancy (B). Densitometric analyses of AQP5 protein levels normalized against $\beta$-actin are summarized in A and B for ovarian expression of AQP5 during studied stages. Comparison of AQP5 expression determined by Western blotting in porcine ovary, between two stages of the cycle and two periods of pregnancy (C). Values are the mean \pm SEM $(n=5)$. ${ }^{a, b}$ Means with different superscripts are significantly different.

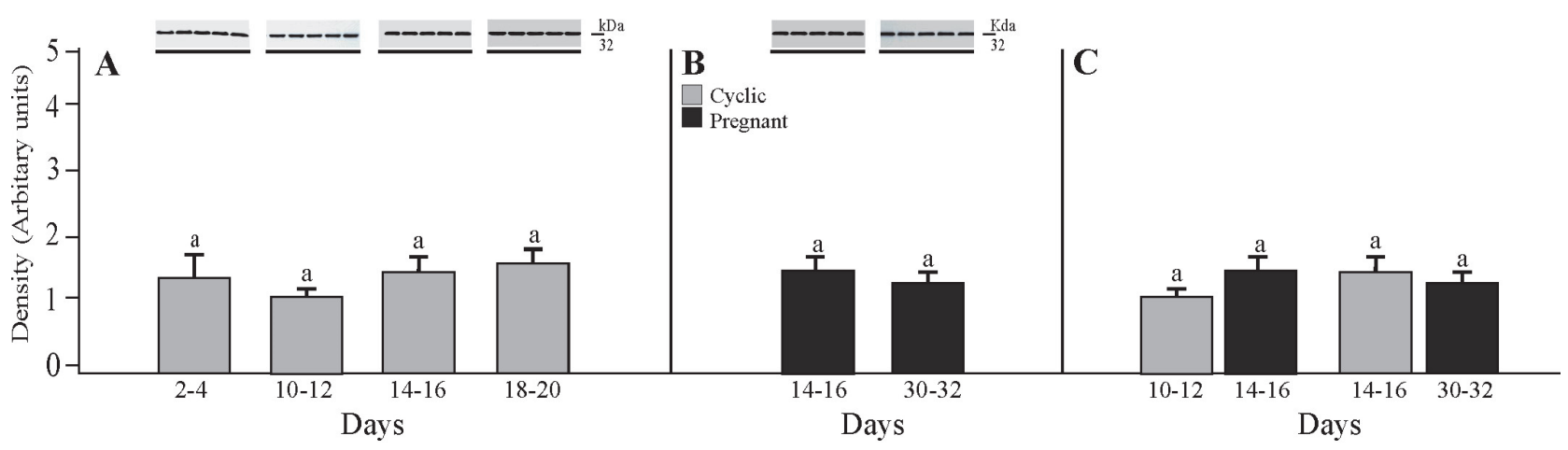

Fig. 4. Western blot analysis of AQP9 expression. Expression of AQP9 assessed by Western blotting in the porcine ovary on Days 2-4, 10-12, 14-16 and 18-20 of estrous cycle (A) as well as on Days 14-16 and 30-32 of pregnancy (B). Densitometric analyses of AQP9 protein levels normalized against $\beta$-actin are summarized in $A$ and $B$ for ovarian expression of AQP9 during studied stages. Comparison of AQP9 expression determined by Western blotting in porcine ovary between two stages of the cycle and two periods of pregnancy (C). Values are the mean $\pm \operatorname{SEM}(n=5)$.

AQP5 was localized in the plasma membranes of granulosa cells and flattened follicle cells of the primordial follicles in the ovary (Fig. 1H-M). As a positive control, AQP5 antibody noticeably stained (Fig. $1 \mathrm{~N}$ ) the apical plasma membrane of the type I pulmonary epithelial cells of the pig. The expression of AQP5 protein did not change between Days 2-4, 10-12 and 14-16 of the estrous cycle but significantly increased $(p<0.05)$ on Days 18-20 (Fig. 3A). The expression of AQP5 tended to be higher on Days 14-16 $(p=0.07)$ than on Days 10-12 (Fig. 3A). The expression of AQP5 did not significantly differ during Days 14-16 and 30-32 of pregnancy (Fig. 3B) and also when compared to middle and late stages of the luteal phase (Fig. 3C). Interestingly, comparison of the level of the AQP1 protein expression with that of the AQP5 in ovaries during the estrous cycle and early pregnancy showed a similar pattern. The highest expression of these proteins was detected on Days
18-20 of the estrous cycle.

AQP9 immunoreactivity was observed in the granulosa cells of the developing follicles in the ovary (Fig. 1O-T). As a positive control, in the liver tissues of pigs, AQP9 staining was seen at the sinusoidal surfaces of hepatocyte plates (Fig. 1U). The expression of AQP9 did not change significantly between all days of the estrous cycle (Fig. 4A) and pregnancy (Fig. 4B) as well as when compared during the onset and the end of implantation process to mid- and late-luteal phases of the estrous cycle (Fig. 4C).

\section{Discussion}

This study demonstrates that AQP1 and 5 protein expression in the porcine ovary is altered during different phases of the estrous cycle and early pregnancy. The high level of AQP1 and 5 expression in porcine 
ovary on Days 18-20 of the estrous cycle may be responsible for fluid balance within the pig ovary. In particular, at the time when preovulatory follicles are developed.

The expression of AQP5 was previously observed in the ovary of pigs, mice and rats (Skowronski et al. 2009, Zhang et al. 2013, Starowicz et al. 2014). The results of several studies support the regulatory influence of steroid hormones on AQP1 mRNA and protein expression in female reproductive system (Li et al. 1997, Lindsay and Murphy 2006, Jablonski et al. 2003). As reported by Kobayashi et al. (2006), AQP5 expression could be activated by estrogen, and estrogen response elements have been identified in AQP5 promoter regions in the uterus.

We hypothesized that within the pig ovary, the AQP1 and AQP5 are localized in different cells populations, in the endothelial and granulosa cells respectively, suggesting their distinct or collaborative roles in follicular development. It is known that rates of water transport into the antral cavity of the follicle are 3.5 fold greater than of inulin (a complex of carbohydrate restricted to the extracellular compartment) (McConnel et al. 2002). In experiment conducted by Clark et al. (1975) the number of large follicles remained low through Days 2-8 (luteogenesis), and 14 of the estrous cycle, but increased at Day 20 (folliculogenesis). In sheep, as in other mammals FSH appears necessary for transition of the small antral to larger follicles (McNatty et al. 2007). Cyclical variations in the levels of progesterone, estrogens and FSH presumably are associated with the observed changes in follicular development (Stabenfeldt et al. 1969, Tillson et al. 1970, Henricks et al. 1972). The progression of the follicle from the preovulatory to the peri-ovulatory state is initiated by $\mathrm{LH}$ in response to the estrogens secreted by the grooving follicle. Recently, Thoroddsen et al. (2011) described mRNA levels of AQP1-4 measured in separated human granulosa and theca cells during precise stages of human ovulation and described localization of AQP1-4 proteins in intact human follicles. All four AQPs were expressed in both granulosa and theca cells during ovulation. McConnel et al. (2002) confirmed presence of AQPs in rat granulosa cells, thus suggesting that water permeability of antral follicles occurs primarily through transcellular mechanism, which may be mediated by AQP7, 8 and 9 . Moreover, presence of AQP9 in granulosa cells suggests that rapid transport of small neutral molecules might be important in the follicle development (Huang et al. 2006,
Qu et al. 2010).

In the ovary, AQP9 presence has been less documented. We have shown its expression in the pig ovarian cells but we did not noted significant differences between studied periods despite of differentiated concentration of ovarian steroids $\left(\mathrm{P}_{4}\right.$ and $\left.\mathrm{E}_{2}\right)$ in plasma of experimental pigs. The role of sex hormones in the regulation of AQP9 expression in ovarian structures has not been fully characterized. However, it is known that the promoter region of AQP9 contains a putative steroid hormone-binding element (Tsukaguchi et al. 1998). In addition, sex linked differences of AQP9 expression in the liver have been reported by Nicchia et al. (2001) suggesting that AQP9 is under control of androgens. Qu et al. (2010) indicated that hyperandrogenism in follicular fluid of women with polycystic ovary syndrome inhibited AQP9 expression in granulosa cells. In contrast, estrogen replacement is sufficient to AQP9 expression after castration (Oliviera et al. 2005, Picciarelli-Lima et al. 2006). Collectively, it seems that expression of AQP9 in the ovarian follicular cells in question is constitutive in pigs during the estrous cycle and early pregnancy. Nevertheless, this statement remains to be verified in further studies.

Our present study may suggest that estrogens or progesterone balance is important in regulation of AQP1, 5 and 9 expression. For example, it is reasonably to speculate that expression of these proteins might be regulated by progesterone during the luteal phase. This suggestion confirms the expression results in porcine ovary with early pregnancy. In pregnant gilts, expression of AQP1, 5 and 9 did not change significantly in comparison with different Days of the estrous cycle. The role of ovarian follicles during pregnancy is controversial. On the one hand, Nara et al. (1981) have shown that removal of follicles did not alter the duration of gestation and littler size in pigs. On the other hand, in later studies by Duda et al. (2004) and Knapczyk et al. (2008), it has been reported that estrogen receptor $\alpha$ and androgen receptor proteins are present in the porcine granulose cells on Days 10, 18, 32 and 90 post coitum. The authors indicated that estrogens and androgens are essential for the maintenance of a pregnancy and that ovarian follicles are important during pregnancy. Research conducted by Wiesak et al. (1992) demonstrated that the distribution of follicles in cyclic and pregnant pigs differed. The ovaries of pregnant pigs contained a greater number of large follicles $(>4 \mathrm{~mm}$ ) than that on Day 12 of cyclic pigs. Small follicles from 
Day 20 and Day 30 of pregnant pigs produced significantly more progesterone than large follicles. A similar relationship was also evident among follicles on Day 12 of the estrous cycle, but not on Day 12 of pregnancy (Wiesak et al. 1992).

In this regards, our data provide the first evidence showing the semi-quantitative analysis of expression and localization of AQP1, 5, and 9 in porcine follicles during the estrous cycle and early pregnancy. These AQPs are localized in different cells populations, the endothelial and granulosa cells. Moreover, we suggest that AQP1 and AQP5 proteins might be involved in follicular development in pigs. Therefore, the further research is required to elucidate the detailed physiological function of AQPs in the pig ovary during the estrous cycle and early pregnancy.

\section{Conflict of Interest}

There is no conflict of interest.

\section{Acknowledgements}

This research was supported by the National Science Center (grant numbers 2013/09/B/NZ9/03129 and 5280206.806).

\section{References}

AGRE P, KING LS, YASUI M, GUGGINO WB, OTTERSEN OP, FUJIYOSHI Y, ENGEL A, NIELSEN S: Aquaporin water channels-from atomic structure to clinical medicine. J Physiol 542: 3-16, 2002.

AKINS EL, MORRISSETTE MC: Gross ovarian changes during estrous cycle of swine. Am J Vet Res 29: 1953-1957, 1968.

CARBREY JM, AGRE P: Discovery of the aquaporins and development of the field. Handb Exp Pharmacol 190: 3-28, 2009.

CARBREY JM, GORELICK-FELDMAN DA, KOZONO D, PRAETORIUS J, NIELSEN S, AGRE P: Aquaglyceroporin AQP9: Solute permeation and metabolic control of expression in liver. Proc Natl Acad Sci USA 100: 2945-2950, 2003.

CLARK JR, FIRST NL, CHAPMAN AB, CASIDA LE: Ovarian follicular development during the estrous cycle in gilts following electrocautery of follicles. J Anim Sci 41: 1105-1111, 1975.

DUDA M, BUREK M, GALAS J, KOZIOŁ K, KOZIOROWSKI M, SŁOMCZYŃSKA M: Immunohistochemical localization of androgen receptor and aromatase in the ovary of the pregnant pig. Reprod Biol 4: 289-298, 2004.

GREENWALD GS, MOOR RM: Isolation and preliminary characterization of pig primordial follicles. $J$ Reprod Fertil 87: 561-571, 1989.

HENRICKS DM, GUTHRIE HD, HANDLIN DL: Plasma estrogen, progesterone and luteinizing hormone levels during the estrous cycle in pigs. Biol Reprod 6: 210-218, 1972.

HUANG HF, HE RH, SUN CC, ZHANG Y, MENG QX, MA YY: Function of aquaporins in female and male reproductive systems. Hum Reprod 6: 785-795, 2006.

JABLONSKI EM, MCCONNELL NA, HUGHES FM Jr, HUET-HUDSON YM: Estrogen regulation of aquaporins in the mouse uterus: potential roles in uterine water movement. Biol Reprod 69: 1481-1487, 2003.

JABLONSKI EM, WEBB AN, MCCONNELL NA, RILEY MC, HUGHES FM Jr: Plasma membrane aquaporin activity can affect the rate of apoptosis but is inhibited after apoptotic volume decrease. Am J Physiol 286: C975-C985, 2004.

KNAPCZYK K, DUDA M, DURLEJ M, GALAS J, KOZIOROWSKI M, SLOMCZYNSKA M: Expression of estrogen receptor alpha (ERalpha) and estrogen receptor beta (ERbeta) in the ovarian follicles and corpora lutea of pregnant swine. Domest Anim Endocrinol 35: 170-179, 2008.

KOBAYASHI M, TAKAHASHI E, MIYAGAWA S, WATANABE H, IGUCHI T: Chromatin immunoprecipitationmediated target identification proved aquaporin 5 is regulated directly by estrogen in the uterus. Genes Cells 11: 1133-1143, 2006.

LI XJ, YU HM, KOIDE SS: Regulation of water channel gene (AQP-CHIP) expression by estradiol and anordiol in rat uterus. Biochem Mol Biol Internat 32: 586-592, 1997. 
LINDSAY LA, MURPHY CR: Redistribution of aquaporins 1 and 5 in the rat uterus is dependent on progesterone: a study with light and electron microscopy. Reprod 131: 369-378, 2006.

MCCONNELL NA, YUNUS RS, GROSS SA, BOST KL, CLEMENS MG, HUGHES FM Jr: Water permeability of an ovarian antral follicle is predominantly transcellular and mediated by aquaporins. Endocrinol 143: 2905-2912, 2002.

MCNATTY KP, READER K, SMITH P, HEATH DA, JUENGEL JL: Control of ovarian follicular development to the gonadotrophin-dependent phase: a 2006 perspective. Soc Reprod Fertil Suppl 64: 55-68, 2007.

NARA BS, DARMADJA D, FIRST NL: Effect of removal of follicles, corpora lutea or ovaries on maintenance of pregnancy in swine. J Anim Sci 52: 794-801, 1981.

NICCHIA GP, FRIGERI A, NICO B, RIBATTI D, SVELTO M: Tissue distribution and membrane localization of aquaporin-9 water channel: evidence for sex-linked differences in liver. J Histochem Cytochem 49: 1547-1556, 2001.

NIELSEN S, KING LS, CHRISTENSEN BM, AGRE P: Aquaporins in complex tissues. II. Subcellular distribution in respiratory and glandular tissues of rat. Am J Physiol 273: C1549-C1561, 1997.

NOGUCHI M, YOSHIOKA K, ITOH S, SUZUKI C, ARAI S, WADA Y, HASEGAWA Y, KANEKO H: Peripheral concentration of inhibin A, ovarian steroids and gonadotropins associated with follicular development throughout the estrous cycle of the sow. Reprod 139: 153-161, 2010.

OLIVEIRA CA, CARNES K, FRANCA LR, HERMO L, HESS RA: Aquaporin-1 and -9 are differentially regulated by estrogen in the efferent ductile epithelium and initial segment of the epididymis. Biol Cell 97: 385-395, 2005.

PICCIARELLI-LIMA P, OLIVEIRA AG, REIS AM, KALAPOTHAKIS E, MAHECHA GA, HESS RA, OLIVEIRA CA: Effects of 3-beta-diol, an androgen metabolite with intrinsic estrogen-like effects, in modulating the aquaporin-9 expression in the rat efferent ductules. Reprod Biol Endocrinol 4: 51, 2006.

PRUNIER A, BONNEAU M, ETIENNE M: Effects of age and live weight on the sexual development of gilts and boars fed two planes of nutrition. Reprod Nut Dev 27: 689-700, 1987.

QU F, WANG FF, LU XE, DONG MY, SHENG JZ, LV PP, DING GL, SHI BW, ZHANG D, HUANG HF: Altered aquaporin expression in women with polycystic ovary syndrome: hyperandrogenism in follicular fluid inhibits aquaporin-9 in granulosa cells through the phosphatidylinositosol 3-kinase pathway. Hum Reprod 25: 1441$1450,2010$.

RODGERS RJ, IRVING-RODGERS HF: Formation of the ovarian follicular antrum and follicular fluid. Biol Reprod 82: 1021-1029, 2010.

SKOWRONSKI MT: Distribution and quantitative changes in amounts of aquaporin 1, 5 and 9 in the pig uterus during the estrous cycle and early pregnancy. Reprod Biol Endocrinol 8: 109, 2010.

SKOWRONSKI MT, LEBECK J, ROJEK A, PRAETORIUS J, FÜCHTBAUER EM, FROKIAER J, NIELSEN S: AQP7 is localized in capillaries of adipose tissue, cardiac and striated muscle:implicaions in glycerol metabolism. Am J Physiol 292: F956-F965, 2007.

SKOWRONSKI MT, KWON TH, NIELSEN S: Immunolocalization of aquaporin 1,5 and 9 in the female pig reproductive system. J Histochem Cytochem 57: 61-67, 2009.

SKOWRONSKI MT, SKOWRONSKA A, NIELSEN S: Fluctuation of aquaporin 1, 5 and 9 expression in the pig oviduct during the estrous cycle and early pregnancy. J Histochem Cytochem 59: 419-427, $2011 \mathrm{a}$.

SKOWRONSKI MT, FRACKOWIAK L, SKOWRONSKA A: Expression of aquaporin 1 in the pig peri-ovarian vascular complex during the estrous cycle and early pregnancy. Reprod Biol 11: 210-223, $2011 \mathrm{~b}$.

STABENFELDT GH, AKINS EL, EWING LL, MORRISSETTE MC: Peripheral plasma progesterone levels in pigs during the estrous cycle. $J$ Reprod Fertil 20: 443-449, 1969.

STAROWICZ A, GRZESIAK M, MOBASHERI A, SZOLTYS M: Immunolocalization of aquaporin 5 during rat ovarian follicle development and expansion of the preovulatory cumulus oophorus. Acta Histochem 116: $457-$ 465, 2014.

TERRIS J, ECELBARGER CA, NIELSEN S, KNEPPER MA: Long-term regulation of four renal aquaporins in rats. Am J Physiol 271: F414-F422, 1996. 
THORODDSEN A, DAHM-KÄHLER P, LIND AK, WEIJDEGÄRD B, LINDENTHAL B, MÜLLER J, BRÄNNSTRÖM M: The water permeability channels aquaporins 1-4 are differentially expressed in granulosa and theca cells of the preovulatory follicle during precise stages of human ovulation. J Clin Endocrinol Metab 96: 1021-1028, 2011.

TILLSON SA, ERB RE, NISWENDER GD: Comparison of luteinizing hormone and progesterone in blood and metabolites of progesterone in urine of domestic sows during the estrous cycle and early pregnancy. $J$ Anim Sci 30: 795-805, 1970.

TSUKAGUCHI H, SHAYAKUL C, BERGER UV, MACKENZIE B, DEVIDAS S, GUGGINO WB, VAN HOEK AN, HEDIGER MA: Molecular characterization of a broad selectivity neutral solute channel. J Biol Chem 273: 24737-24743, 1998.

VERKMAN AS: Mammalian aquaporins: diverse physiological roles and potential clinical significance. Expert Rev Mol Med 10: 1-18, 2008.

WEST-FARRELL ER, XU M, GOMBERG MA, CHOW YH, WOODRUFF TK, SHEA LD: The mouse follicle microenvironment regulates antrum formation and steroid production: alterations in gene expression profiles. Biol Reprod 80: 432-439, 2009.

WIESAK T, HUNTER MG, FOXCROFT GR: Ovarian follicular development during early pregnancy in the pig. Anim Reprod Sci 29: 17-24, 1992.

ZHANG D, TAN YJ, QU F, SHENG JZ, HUANG HF: Functions of water channels in male and female reproductive systems. Mol Asp Med 33: 676-690, 2012.

ZHANG H, ZHANG Y, ZHAO H, ZHANG Y, CHEN Q, PENG H, LEI L, QIAO J, SHI J, CAO Z, DUAN E, JIN Y: Hormonal regulation of ovarian bursa fluid in mice and involvement of aquaporins. PLoS One 8: e63823, 2013. 